\title{
Redistribution through Minimum Wage Regulation: \\ An Analysis of Program Linkages and Budgetary Spillovers
}

\author{
Jeffrey Clemens*
}

September 1, 2015

\begin{abstract}
:
Program linkages and budgetary spillovers can significantly complicate efforts to project a policy change's effects. I illustrate this point in the context of recent increases in the federal minimum wage. Previous analysis finds that these particular minimum wage increases had significant effects on employment. Employment declines were sufficiently large that the average earnings of targeted individuals declined. Payroll tax revenues thus also fell. I find that transfers to affected individuals through programs including unemployment insurance, food stamp benefits, and cash welfare assistance changed little. These programs thus offset relatively little of the earnings declines experienced by individuals who lost employment. I discuss how this broad range of spillovers matters for assessing the relevant minimum wage change's welfare implications.
\end{abstract}

*Clemens: University of California at San Diego, Jeffrey Clemens, Economics Department, 950o Gilman Drive \#0508, La Jolla, CA 92093-0508, USA. Telephone: 1-509-570-269o. E-mail: clemens.jeffrey@gmail.com. Special thanks to Jean Roth for greatly easing the navigation and analysis of SIPP data, as made accessible through NBER. Thanks also to Jeff Brown for detailed comments, Julie Cullen, Roger Gordon, and Rob Valetta for helpful conversations, and Michael Wither for invaluable research assistance. I also gratefully acknowledge support from the UCSD Academic Senate through its small grant program. 
Projecting a policy change's effects is an important, but often difficult task. How, for example, will an increase in the minimum wage alter the income distribution? The question is non-trivial in part because a minimum wage increase may alter employment opportunities. For this and other reasons, a minimum wage change's direct, or static, effects are unlikely to be the last word. Further complications arise because the incomes of low-wage workers may include transfer payments through a variety of programs. Benefit reductions may partially offset the gains of those whose earnings rise, while benefit increases may provide a cushion for those who lose their jobs. Program linkages of this sort are this paper's focus.

Comprehensive program evaluation requires a full appreciation of the relevant policy landscape. Tracking a policy change's effects on beneficiary well being, labor supply incentives, and public budgets can thus require devoting significant attention to programs' interrelationships. I illustrate this point in the context of recent increases in the federal minimum wage.

I analyze the program and budgetary spillover effects of recent minimum wage increases using the empirical design developed by Clemens and Wither (2014). Clemens and Wither (2014) use the 2008 panel of the Survey of Income and Program Participation (SIPP) to estimate the effects of the July 2009 increase in the federal minimum wage on the employment and income trajectories of targeted workers. ${ }^{1}$ The former paper devotes considerable attention to assessing its research design's robustness along a variety of dimensions. Taking the research design as given, this paper explores the program and budgetary spillovers associated with both the intended and unintended effects of the July 2009 minimum wage increase.

\footnotetext{
${ }^{1}$ The analysis focuses on the July 2009 increase because the 2008 SIPP panel begins just as the July 2008 increase went into effect. The July 2009 increment was fully binding on roughly half of the U.S. states. Fortuitously for empirical purposes, this was a rare instance in which states that were not affected by the federal increase engaged in very little adjustment of their state-level minimum wage policies over the surrounding period; their minimum wage rates changed modestly between July 2008 and July 2012.
} 
I emphasize two distinct dimensions along which program linkages enter the program evaluation problem. First, the full program landscape shapes the effects of any one policy change on the well-being of the population it targets. ${ }^{2}$ A minimum wage increase, for example, may increase some low-skilled workers' earnings while reducing the earnings of those who lose employment. The well-being of the latter group can depend crucially on the extent to which programs like unemployment insurance and food stamps replace losses in earned income.

In the context of the July 2009 minimum wage increase, I estimate the extent to which the earnings declines of job losers are replaced by income from a variety of safety net programs. I find that safety net programs offset very little of these workers' lost income. While there is weak evidence of an increase in receipt of means tested cash transfer payments, there is no evidence of an increase in the receipt of unemployment insurance benefits, food stamp benefits, or any form of Social Security benefit. This may in part reflect the characteristics of the workers the minimum wage affects. A significant fraction, for example, are not their households' primary earners (Sabia and Burkhauser, 2010). Further, because their labor force participation is often irregular, many may not be eligible for unemployment insurance. Among those who are eligible, benefit levels may be sufficiently small that they are not worth incurring the associated stigma and/or administrative hassles (Moffitt, 1983; Aizer, 2007; Bhargava and Manoli, Forthcoming; Manoli and Turner, 2014).

Public budgets are a second channel through which program spillovers can have policy relevance. Estimates of a proposed policy change's budgetary effects are featured prominently in the policy making process. The Congressional Budget Office $(\mathrm{CBO})$ and Joint Committee on Taxation (JCT) devote considerable effort to assessing proposals'

\footnotetext{
${ }^{2}$ The formulation of the program evaluation problem presented by Hendren (2013) draws out this point mathematically. The current paper's empirical analysis illustrates how difficult tracing out the relevant program linkages can be in practice.
} 
budgetary consequences, and do so at the behest of the congressmen and women whose decisions they inform. The debate over the Affordable Care Act is illustrative, as claims associated with the act's total budgetary impact and the 10-year cost of its coverage provisions were prominent sources of controversy (Gruber, 2011).

Clemens and Wither (2014) find, initially surprisingly, that the July 2009 minimum wage increases were followed by declines in the average earnings of targeted workers. The factors underlying this result are discussed in that paper at length. First, job losses were greater than typically estimated. This likely reflects, at least in part, the weak labor markets in which these minimum wage increases were implemented. Second, targeted workers became marginally more likely to work without pay, as in unpaid internships. Third, affected workers' subsequent income growth appears to have been slowed, likely by some combination of lost experience and within-job development of human capital.

The estimated declines in average earnings translate directly into reduced payroll tax collections. A within-sample estimate of the decline in payroll tax collections from targeted workers amounts to $\$ 2.5$ billion per year. ${ }^{3}$ This estimate is subject to considerable uncertainty, as the associated 95 percent confidence interval extends from $\$ 1$ billion to $\$ 4$ billion. Increases in benefit payouts add roughly $\$ 1$ billion to the annual within-sample budgetary spillover. The confidence interval on this estimate extends from $-\$ 1$ billion to \$3 billion.

The overall fiscal effects of the minimum wage changes under analysis could include a variety of additional factors. Further effects on tax collections may be realized through changes in personal income tax payments, Earned Income Tax Credit (EITC) receipt, and the corporate income tax payments of the targeted workers' employers. Estimating such

\footnotetext{
3By "within-sample" I mean that this estimate is specific to the changes in earnings associated with the July 2009 minimum wage increases, which were binding in just over half of the states. It does not involve an attempt to extrapolate the estimates to the full set of minimum wage increases that took place between 2007 and 2009.
} 
effects would require more assumptions than those needed to infer payroll tax changes. For the targeted workers, payroll tax changes can be safely assumed to scale proportionately with monthly earned income. ${ }^{4}$ Personal income tax payments would depend further on household structure, baseline levels and changes in the earnings of family members, and the aggregation of earnings over the tax year. Corporate tax payments may be affected by a broad range of responses to minimum wage changes which are beyond this paper's scope. The substantial number of channels through which a minimum wage change may alter tax collections further demonstrates the revenue estimation problem's difficulty. 5

I conclude by emphasizing two additional issues. First, payroll tax spillovers have implications for program-specific accounts. Specifically, they affect the trust fund balances of Social Security, Medicare, and state Unemployment Insurance programs. From the perspective of pure public finance theory, the line between trust fund revenue and general revenue may be a distinction without a difference. It is a distinction, however, with salient legal implications. Social Security's Trustees project, for example, that the Disability Insurance (DI) Trust Fund will be exhausted in 2016. Policy changes that alter DI payroll tax revenues thus have short-run implications for the benefits that will be legally payable absent Congressional action.

Second, the minimum wage increases I analyze were implemented during arguably the weakest U.S. labor market in 75 years. This points to yet another difficulty faced by

\footnotetext{
4The earnings of these workers are far below the annual earnings thresholds associated with payroll tax collections for Social Security. As discussed later, earnings thresholds associated with payroll tax collections for state unemployment insurance programs are much lower and hence more likely to bind.

${ }^{5}$ Hendren (2013), in applying his framework to EITC expansions and changes in the top income tax rates, provides a complementary discussion of two relevant sources of difficulty. In his discussion of EITC expansions, for example, Hendren mentions the need to estimate changes in the take up of social programs including SSDI and foodstamps. In his discussion of top income tax rates, he highlights the need to either directly estimate a policy change's spillover effects or assume them away. As Hendren notes, many empirical settings are such that causal estimates of a policy change's direct effects can only be obtained under a no-spillover assumption.
} 
the $\mathrm{CBO}$, the JCT, and other agencies charged with informing the policy making process. Policy proposals' effects may depend to a significant degree on the macroeconomic context in which they are implemented.

The paper proceeds as follows. Section 1 elaborates on the relevance of program and budgetary spillovers to the program evaluation problem. Section 2 describes the historical background of the minimum wage increases under analysis. Section 3 describes the data sources and empirical methodology. Section 4 presents summary statistics describing the analysis sample. Section 5 presents the results, Section 6 considers their aggregate budgetary implications, and Section 7 concludes.

\section{A Discussion of the Policy Relevance of Program Link- ages and Budgetary Spillovers}

Policy makers regularly utilize policy instruments with overlapping ends. This is particularly true in the realm of safety net programs. Support for low-income house-

holds comes through transfers made in cash and in kind, through programs operated at the local, state, and federal levels, and through both regulatory measures and taxfinanced programs. In a policy environment such as this, tracking program linkages and budgetary spillovers can be both important and difficult.

The central issues of interest involve program linkages' relevance for cost-benefit analysis. Comprehensive cost-benefit analysis requires assessing the final outcomes associated with the intended and unintended consequences of a policy change, including those that are unexpected. In the context of minimum wage increases, for example, one must know the extent to which the incomes of job losers will be cushioned by transfers through tax-financed programs. Similarly, one must know the extent to which the gains to those who remain employed will be augmented by the Earned Income Tax Credit 
and/or eroded by cash welfare phase-outs. Hendren's (2013) framework for evaluating a policy change's welfare implications makes such effects' potential relevance readily apparent.

Related issues have been emphasized in recent work on a range of different issues. Kline and Walters (2014), for example, note that both the benefits and net costs of the federal Head Start program depend on the extent to which it displaces state government programs. Baicker and Staiger (2005) make a similar point in the context of federal funds intended for hospitals that serve low-income populations; these federal funds sometimes displaced state funds rather than augmenting them. A broader literature on the flypaper effect considers the extent to which intergovernmental grants "stick" in the spending areas they were intended to target (as opposed to being shifted to other purposes). Inman (2008) and Hines and Thaler (1995) provide reviews of this substantial literature. Popular applications within this literature include an analysis of transportation grants by Knight (2002) and studies of education funding by Gordon (2004) and Baicker and Gordon (2006).

Policy complementarities can be quite directly relevant from the perspective of optimal policy design. Lee and Saez (2012), for example, explore the conditions under which the minimum wage and tax-financed wage subsidies should be viewed as complementary approaches to anti-poverty policy rather than as substitutes. Clemens (2015) highlights the interplay between state Medicaid expansions and the severity of the adverse selection problem in insurance markets governed by community rating regulations. In these regulatory contexts, it is worth noting that the entirety of a measure's budgetary effects are indirect, as regulation per se involves no direct appropriations.

Additionally, budgetary spillovers may be relevant from a legal perspective even when they are superfluous from a theoretical optimal policy perspective. Legal divisions between federal payroll and income tax revenues can matter, for example, due 
to the rules governing the Social Security and Medicare trust funds. Specifically, nonnegative trust fund balances are required in order for scheduled benefits to be paid in full. Intergovernmental relations can also become relevant when federal, state, and local governments attempt to shift costs to one another (Baicker, Clemens, and Singhal, 2012). As with legal distinctions between trust funds and general revenues, shifts between state and federal governments can matter in practice due to differences in fiscal or budgetary institutions. States face balanced budget requirements, for example, which often bind policy makers during economic downturns (Poterba, 1994; Clemens and Miran, 2012).

Finally, long-run budgetary spillovers can result from safety net interventions which generate improvements in human capital. Recent evidence from a variety of domains suggests that such considerations can be quite important. Examples include the long run effects of Medicaid expansions (Brown, Kowalski, and Lurie, 2015), investments in

teacher quality (Chetty, Friedman, and Rockoff, 2013), and environmental regulations (Isen, Rossin-Slater, and Walker, 2014) on beneficiaries' future earnings. By increasing future earnings, some of these programs' initial expenditures can be offset by future tax revenues. Future spending offsets have similarly been identified in the health insurance context (Chandra, Gruber, and McKnight, 2010). Recognizing and quantifying such effects can thus be essential for executing a comprehensive cost benefit analysis.

\section{Background on the Late 2000 Increases in the Federal Minimum Wage}

This paper illustrates the relevance of program and budgetary spillovers in the context of recent increases in the federal minimum wage. This section describes the minimum wage increases underlying the empirical analysis. Both the current section and the next, which outlines the methodology, draw liberally on the text of Clemens and Wither 
(2014), in which the empirical approach was initially developed.

I estimate the program and budgetary spillovers resulting from recent minimum wage increases using variation driven by federally mandated increases in the minimum wage rates applicable across the U.S. states. On May 25, 2007, Congress legislated a series of minimum wage increases through the "U.S. Troop Readiness, Veterans' Care, Katrina Recovery, and Iraq Accountability Appropriations Act." Increases went into effect on July 24 th of 2007,2008 , and 2009. In July 2007 , the federal minimum rose from $\$ 5.15$ to $\$ 5.85$; in July 2008 it rose to $\$ 6.55$, and in July 2009 it rose to $\$ 7.25$.

Figure 1, which appears in Clemens and Wither (2014), shows the division of states into those that were and were not bound by changes in the federal minimum wage. The designation is based on whether a state's January 2008 minimum was below $\$ 6.55$, rendering it partially bound by the July 2008 increase and fully bound by the July 2009 increase. Just over half, specifically 27 , of the states fit this description.

Figure 2, which also appears in Clemens and Wither (2014), shows the time paths of the average effective minimum wages in the states to which the "bound" designation does and does not apply. The average minimum wage in unbound states exceeded the minimum applicable in the bound states prior to the passage of the 2007 to 2009 federal increases. These states voluntarily increased their minimums well ahead of the required schedule. On average, the effective minimum across these states had surpassed $\$ 7.25$ by January of 2008. This group's effective minimums rose by an average of roughly 20 cents over the period analyzed in this paper, which extends for 4 years beginning in August 2008. By contrast, bound states saw their effective minimums rise by nearly the full, legislated \$0.70 on July 24, 2009. As borne in mind throughout, these states experienced differentially binding minimum wage increases in both July 2008 and July 2009. The estimation framework, described in the following section, may thus capture both the July 2009 increase's full effect and some dynamic effects of the increase from July 2008. 
A potential threat to this paper's estimation framework, discussed in greater detail in Clemens and Wither (2014), is the possibility that bound and unbound states were differentially affected by the Great Recession. To explore this concern's relevance, Figure 3 presents data from the Bureau of Labor Statistics (BLS), the Bureau of Economic Analysis (BEA), and the Federal Housing Finance Agency (FHFA) on the macroeconomic experiences of bound and unbound states during the Great Recession. ${ }^{6}$ Throughout this time period, unbound states have higher per capita incomes, but lower employment-topopulation ratios, than do bound states. While the economic indicators of both groups turned significantly for the worse over the recession's course, bound states were less severely impacted by the Great Recession than were unbound states. It is particularly apparent that unbound states had relatively severe housing bubbles (Panel C). These macroeconomic factors would, if controlled for insufficiently, tend to bias the magnitudes of estimated effects on labor market outcomes towards zero. The following section describes the empirical strategy for addressing this concern.

\section{Estimation Framework}

I estimate the effects of minimum wage increases using data from the 2008 panel of the Survey of Income and Program Participation (SIPP). I use the same samples utilized for the analysis in Clemens and Wither (2014). As in the previous section, much of what follows is taken directly from the prior paper's text. The sample is restricted to individuals aged 16 to 64 for whom the relevant employment, earnings, and transfer income data are available for at least 36 months between August 2008 and July 2012. For each individual, this yields up to 12 months of data preceding the July 2009 increase in

\footnotetext{
${ }^{6}$ Like the previous figures, this figure also appears in Clemens and Wither (2014). All series are weighted by state population so as to reflect the weighting implicit in the individual-level regression analysis.
} 
the minimum wage. I use these 12 months of baseline wage, hours, and earnings to data identify low-skilled workers who were directly targeted by the relevant increases in the minimum wage. Specifically, I analyze samples of individuals whose average baseline wage rates were less than $\$ 7.50$.

On the sample of workers with average baseline wages below $\$ 7.50$, I estimate the following, dynamic difference-in-differences regression:

$$
\begin{aligned}
Y_{i, s, t} & =\sum_{p(t) \neq 0} \beta_{p(t)} \text { Bound }_{s} \times \text { Period }_{p(t)} \\
& +\alpha_{1_{s}} \text { State }_{s}+\alpha_{2_{t}} \text { Time }_{t}+\alpha_{3_{i}} \text { Individual }_{i}+\mathbf{X}_{\mathbf{s}, \mathbf{t}} \gamma+\varepsilon_{i, s, t} .
\end{aligned}
$$

The regression controls for the standard features of difference-in-differences estimation, namely sets of state, State $_{s}$, and time, Time ${ }_{t}$, fixed effects. The SIPP allows me to control for individual fixed effects, Individual ${ }_{i}$, rendering controls for individual-level, timeinvariant characteristics redundant. The vector $\mathbf{X}_{\mathbf{s}, \mathbf{t}}$ contains time varying controls for each state's macroeconomic conditions. In the baseline specification, $\mathbf{X}_{\mathbf{s}, \mathbf{t}}$ includes the FHFA housing price index, which proxies for the state-level severity of the housing crisis. ${ }^{7}$

Equation (1) allows for dynamics motivated by graphical evidence presented in Figure 4. The figure shows that the prevalence of wages between the old and new federal minimum declined rapidly beginning in April 2009. This motivates a characterization of May to July 2009 as a "Transition" period. Prior months correspond to the baseline, or

\footnotetext{
7It is not uncommon for minimum wage studies to control directly for a region's overall employment or unemployment rate. Conceptually, it seems preferable to exclude such variables because they may be affected by the policy change of interest. The housing price index is a conceptually cleaner, though still imperfect, proxy for time varying economic conditions that were not directly affected by minimum wage changes. Clemens and Wither (2014) show that their baseline employment results are essentially unaffected by taking a variety of alternative approaches to controlling for heterogeneity in macroeconomic conditions.
} 
period $p=0$. August 2009 through July 2010 is period Post 1 and all subsequent months are period Post 2. The primary coefficients of interest are $\beta_{\text {Post 1 }(t)}$ and $\beta_{\text {Post 2(t) }}$, which describe the differential evolution of the dependent variable in states that were bound by the new federal minimum relative to states that were not bound. The standard errors on these coefficients are estimated allowing for the errors, $\varepsilon_{i, s, t}$, to be correlated at the state level.

Clemens and Wither (2014) explore the robustness of the estimates generated by equation (1) along a variety of margins. Within the difference-in-differences framework itself, this includes several approaches to controlling for macroeconomic trends. The analysis checks further for the possibility that demographic differences between low-skilled workers in bound and unbound states might bias estimated employment effects due to differenial demographic trends. The analysis allows, for example, for differential trends associated with age-specific dummy variables, as well as with dummy variables for individuals' modal industry of employment at baseline. Clemens and Wither (2014) further demonstrate the robustness of the estimates to implementing a triple difference framework in which they use slightly higher skilled workers as a within-state control group. In light of the robustness observed in the prior analysis, the current paper explores additional outcomes using the former paper's baseline specification.

\section{Baseline Summary Statistics}

Table 1 presents summary statistics describing the samples on which I estimate equation (1). Column 1 presents summary statistics for individuals living in states that were bound by the July 2009 increase in the federal minimum wage, while column 2 presents summary statistics for those in states that were not. The data describe these individuals' characteristics over the baseline and transition periods, which extend from August 2008 
to July 2009 .

Row 1 shows that, prior to the minimum wage increase, individuals in bound states were far more likely to have wage rates between the old and new federal minimum. Individuals in bound states reported wage rates in this range in 37 percent of months while individuals in unbound states reported wage rates in this range in 22 percent of months. The latter number is not zero due to a combination of measurement error in self-reported wages and the fact that not all jobs are covered by minimum wage legislation (e.g., workers who receive tips). Figure 4 shows that these probabilities converge following the implementation of the new federal minimum. The convergence occurs between April and July 2009, which underlies my treatment of May through June 2009 as a transition period during which wages adjusted to the new federal minimum.

Row 2 shows that the average total monthly income of individuals in bound and unbound states were quite similar at baseline. In-sample individuals in bound states had average monthly incomes of $\$ 740$, while those in unbound states had average monthly incomes of $\$ 750$. The samples differ moderately in terms of this income's composition. The average earned income of in-sample individuals in bound states was roughly $\$ 50$ higher than the earned income of those in unbound states, reflecting moderately higher baseline employment probabilities. Individuals in unbound states average roughly $\$ 50$ more in income from other sources, which include asset and transfer income.

\section{Analysis of the July 2009 Minimum Wage Increase's Pro- gram and Budgetary Spillover Effects}

This section presents estimates of $\beta_{\text {Post 1 (t) }}$ and $\beta_{\text {Post } 2(t)}$ from equation (1). The estimates describe the differential evolution of the outcomes of low-skilled workers in bound states relative to the outcomes of low-skilled individuals in unbound states. Ini- 
tial results describe changes in targeted workers' total incomes, with a breakdown across broad sources. I then present results describing changes in program participation, the magnitude of benefits received, and payroll tax payments.

\subsection{Income and Its Sources}

Table 2 presents estimates of the minimum wage increase's effects on the average monthly incomes of targeted workers. The estimates in column 1 show that, on average, targeted workers' incomes declined by $\$ 90$ over the first year and by $\$ 140$ over subsequent years. The analysis in Clemens and Wither (2014) presents this finding and considers its underlying causes in detail. Four factors appear to underlie this initially surprising result. First, employment losses were greater than typically estimated. As noted above, this likely reflects the weak labor markets in which these minimum wage increases were implemented. Second, there is some evidence of an increase in the probability that targeted individuals work without pay, as in internships. The total effect on the probability of having no earnings is thus quite large. Third, the minimum wage increase's direct effects on wages appear to have been smaller than typically assumed. This may reflect a combination of legal coverage gaps and evasion. Finally, affected workers' subsequent income growth appears to have been slowed by some combination of losses of experience and within-job development of human capital.

Columns 2 through 4 decompose the estimated effect on total income into several components. The estimated effect on earned income is modestly larger than the estimated effect on total income over the medium run. During period Post 1, earned income and total income both declined by $\$ 90$. Over subsequent years, the total estimated decline in average earned income was $\$ 165$. This decline in earned income was partially offset by changes in asset and other income sources, yielding the $\$ 140$ decline in total income. The key takeaway from these results is that increases in income from other 
sources offset relatively little of the decline in earned income. Targeted individuals who lost employment thus experienced substantial declines in total income.

Figures 5 and 6 present estimates which describe the minimum wage increase's shortand medium-run effects on the distribution of earnings across low-skilled workers. The dots in Figure 5 are estimates of $\beta_{\text {Post } 1(t)}$ from equation (1), while the dots in Figure 6 are estimates of $\beta_{\text {Post 2(t) }}$. The outcome variables are constructed as

$$
Y_{i, s, t}^{j}=1\left\{E^{j-1}<\text { Earnings }_{i, s, t}<E^{j}\right\}
$$

That is, the outcome variable $Y_{i, s, t}^{j}$ is an indicator set equal to 1 if an individual's monthly earnings are in the band between $E^{j-1}$ and $E^{j}$, where each band is a 200 dollar interval. The results can thus be described as estimates of the minimum wage increase's shortand medium-run effects on the earnings distribution's probability mass function.

The estimates are instructive regarding the mechanisms emphasized by Clemens and Wither (2014) in their analysis of the forces underlying the decline in targeted workers' average earnings and incomes. Figure 5 reveals that the bulk of the $\$ 90$ short-run decline in average earnings is associated with increases in the probability of reporting zero, or very near zero, earnings. The increase in the mass of individuals reporting earnings below $\$ 200$ comes primarily from declines in the probability of reporting slightly higher earnings and declines in the probability of earnings between $\$ 1000$ and $\$ 1200$. The latter earnings band includes the earnings associated with full time work at the targeted workers' old minimum wage of $\$ 6.55$. There is weak evidence of a slight increase in the probability of earnings between $\$ 1200$ and $\$ 1400$, which includes the earnings associated with full time work at the new minimum wage of $\$ 7.25$. The figure further reveals that there was essentially no movement at points higher in the earnings distribution.

Figure 6 reveals two relevant phenomena that emerge over the medium run. First, there is a modest increase, relative to the short-run, in the probability of having zero 
or near zero earnings. Second, there is a shift in where this mass comes from. The short-run estimates reveal that the earnings distribution shifted exclusively away from earnings levels that could be generated by full or part-time work at the initial minimum wage. Over the medium run, much of the shift comes from earnings levels that could be generated by working full time at wages modestly or moderately higher than the new minimum. Low-skilled workers in bound states were thus less likely than low-skilled workers in unbound states to transition into higher-wage employment. As discussed by Clemens and Wither (2014), this likely reflects the effects of declines in the accumulation of experience and skills more generally. Such effects may be substantial because most minimum wage workers are on the steep portion of the wage-experience profile (Murphy and Welch, 1990; Smith and Vavrichek, 1992). ${ }^{8}$

\subsection{Program Spillover Effects}

The results in Table 3 describe the minimum wage increase's effects on program participation rates. Such effects appear to be negligible. Column 1 reports a marginally statistically significant estimate of a 1 percentage point increase in participation in any means tested cash transfer program. Columns 2 through 4 present statistically insignificant and economically negligible effects on the receipt of any assistance through food stamps, unemployment insurance, or any form of Social Security benefit. Column 5 presents the estimated change in the probability of receiving any form of benefit. The coefficient, which implies a 1.2 percentage point increase, is estimated with little precision.

Table 4 presents a similar set of estimates of the minimum wage increase's effects

\footnotetext{
${ }^{8}$ The contrast between the short- and medium-run effects presented in Figures 5 and 6 are broadly consistent with the analysis of Meer and West (2013), who find that the minimum wage's employment effects may best be modeled as effects on the growth of employment rather than as instantaneous effects on its level.
} 
on the dollar value of benefits received. Column 1 reports a marginally statistically significant increase in the value of means tested cash benefits of $\$ 8$ per month. Consistent with the participation results from Table 3 , changes in the value of other benefits received are both economically and statistically indistinguishable from zero. The point estimate for the overall change in average monthly benefits, reported in column 5, is \$12.

How large is this $\$ 12$ change in average monthly benefit receipt? Table 2 presented an estimated decline in average monthly earnings of $\$ 165$. The point estimates thus suggest that public benefits offset roughly 7 percent of this decline. The high end of the 95 percent confidence interval would imply an offset of roughly 20 percent of the decline in earned income. This echoes recent results from Rothstein and Valletta (2014), who find that little of the income lost by individuals who exhausted extended unemployment insurance benefits was recouped through increases in other transfer income. ${ }^{9}$ In Section 6, I further quantify the aggregate implications of this and subsequent estimates of budgetary impacts.

The results in Tables 3 and 4 provide the details underlying Table 2's finding that benefits offset very little of targeted workers' changes in earned income. Two factors seem likely to underlie this outcome. First, the benefits for which job losers are eligible may simply fail to replace a significant fraction of lost income. Second, a combination of stigma, administrative, and informational hurdles may underlie incomplete take-up of benefits for which individuals are eligible (Aizer, 2007; Moffitt, 1983; Bhargava and Manoli, Forthcoming; Manoli and Turner, 2014). Past research on unemployment insurance, for example, finds that roughly two-thirds of those who are eligible ultimately take up benefits (Blank and Card, 1991; Gruber, 1997). Because of their typically limited employment histories, minimum wage workers are less likely than others to be eligible

\footnotetext{
9In both instances, the estimated offset is sufficiently small that the qualitative picture is unlikely to be affected by issues associated with underreported transfer income, which are documented by Meyer, Mok, and Sullivan (2015).
} 
for unemployment insurance in the first place. Similarly, because many minimum wage workers are not their household's primary earners, their earnings may not significantly influence eligibility for cash welfare, food aid, or other forms of means-tested assistance (Burkhauser and Sabia, 2007; Sabia and Burkhauser, 2010).

As I have emphasized throughout, an understanding of program interrelationships can be essential for evaluating a given policy change. In the context of minimum wage increases, the outcomes of individuals who lose employment are an important piece of the picture. If unemployment insurance and means-tested transfers replace losses in these individuals' earned incomes, the downside of minimum wage increases would be softened. The estimates presented above provide evidence that, at least in the context under analysis, job losers were not cushioned against earnings losses.

The results presented in Figure 7 provide further evidence of the minimum wage increase's effect on the distribution of targeted workers' incomes. Like Figure 6, which described changes in the earnings distribution, it presents medium-run estimates of the coefficient $\beta_{\text {Post } 2(t)}$. Figure 7 shows that less mass shifted to incomes between $\$ 0$ and \$200 than shifted to earnings in that range. This suggests some cushioning against the extreme outcome of losing all income. However, this mass appears to collect at incomes between $\$ 200$ and $\$ 400$, suggesting limitations of the safety net cushion on which these individuals were able to draw. ${ }^{10}$

\subsection{Revenue Spillover Effects}

Table 5 presents estimates of the effect of binding minimum wage increases on the payroll taxes paid by targeted workers. Because the SIPP does not directly survey its respondents about tax payments, the estimates are necessarily based on imputations.

\footnotetext{
${ }^{10}$ These outcomes would weigh heavily in standard welfare analyses. The utility functions used in such analyses significantly penalize near zero outcomes due to the degrees of risk aversion they typically assume.
} 
Imputation is straightforward for Social Security and Medicare payroll taxes because affected workers' earnings fall well below the ceilings beyond which these taxes cease to be collected. Further, since these payroll taxes are collected at constant rates, imputing them simply requires scaling earned income. The estimates reported in columns 1 and 2 show that the average estimated earnings declines translate into declines in Social Security and Medicare payroll tax collections of $\$ 21$ and $\$ 5$ per month respectively. I calculate these estimates' aggregate budgetary implications in Section 6 .

Column 3 reports the estimated change in Unemployment Insurance (UI) payroll tax collections. The imputation of UI payroll tax payments is less straightforward than the imputation of Social Security and Medicare payments. I maintain the assumption that the earned income of minimum wage workers falls below the relevant unemployment insurance tax ceilings. Because the relevant ceilings tend to be much lower than the Social Security ceiling, this assumption may not be strictly true. It is unlikely, however, to be violated to a meaningful degree. ${ }^{11}$ A more important limitation is that the relevant payroll tax rates vary across firms and states. These variations, which I am unable to capture, result from states' systems for adjusting firms' UI contribution rates as a function of their layoff histories. Lacking the relevant tax rates, I uniformly apply a rate of 2.5 percent. The estimated decline in average monthly UI tax collections is $\$ 4$.

There are two additional channels through which a minimum wage change might influence tax payments associated with targeted workers. The decline in average incomes is likely associated with modest declines in personal income tax payments. Such effects would depend further on household structure, baseline levels and changes in family members' earnings, and the aggregation of monthly earnings over the tax year. While in principle the SIPP contains sufficient information to construct reasonable estimates

\footnotetext{
${ }^{11}$ The sample's average annual earnings are roughly $\$ 7,000$, which falls below the UI ceiling in the vast majority of states. Additionally, the earnings of low-skilled workers are often split across multiple jobs, further reducing the likelihood of reaching the ceiling for any one job.
} 
of income tax payments, this exercise would require far more assumptions than did the estimation of payroll tax payments.

Changes in targeted workers' earnings are also likely to alter Earned Income Tax Credit (EITC) receipts. Net effects are likely to be modest, reflecting three factors. First, the overall change in earnings was itself relatively modest. Second, many targeted workers are in families with total income sufficient to place them beyond the EITC schedule. Third, some of the remaining families have incomes in the EITC's phase-in range while others have incomes in its phase-out range.

\section{Inferring Aggregate Budgetary Effects}

This section considers the aggregate budgetary effects of the tax and expenditure spillovers estimated in the previous section. Estimates of aggregate budgetary effects require additional non-trivial assumptions and, as a result, come with considerable caveats. Highlighting the uncertainties associated with such exercises, even on a purely within-sample basis, is as much this section's point as are the estimates themselves.

The SIPP population weights reveal that this paper's analysis samples account for roughly 7 percent of the U.S. population aged 16 to 64 . The total U.S. population in this age group was quite close to 200 million during this time period, of which roughly half resided in states bound by the July 2009 increase in the federal minimum wage. There were thus roughly 7 million workers with average baseline wages below $\$ 7.50$ in bound states.

The estimates from the previous section implied a payroll tax spillover of \$29 per individual per month (with a standard error of 8.8), or \$353 per year. The annual insample aggregate effect on payroll tax revenue is thus 7 million $\times \$ 353=\$ 2.5$ billion (with a standard error of roughly $\$ 0.75$ billion). The estimated increase in benefit pay- 
ments was $\$ 12$ per individual per month (with a standard error of 11 ), or $\$ 142$ per year. The annual in-sample aggregate spending effect is thus 7 million $\times \$ 142=\$ 1$ billion (with a standard error of roughly $\$ 1$ billion).

Several considerations highlight the difficulty of developing and further extending such estimates. First, the analysis focuses exclusively on the outcomes of workers targeted by minimum wage increases. Other groups are, of course, either necessarily or potentially affected. The owners and managers of firms hiring minimum wage workers are necessarily affected. These managers (and their customers) are precisely the individuals from whom minimum wage increases seek to generate transfers to low-skilled workers. Their net incomes likely decline as the minimum wage increase affects their labor costs. By contrast, minimum wage increases may result in substitution away from the lowest skilled workers and towards slightly higher skilled workers. Slightly higher skilled workers may thus experience income gains, which would generate offsetting increases in tax collections.

Second, the estimates are internally valid to a very particular set of macroeconomic circumstances. Agencies such as CBO and JCT may be asked to evaluate the effects of proposals like minimum wage increases under a broad range of macroeconomic circumstances. It may thus be appropriate for policy projections to acknowledge uncertainty associated with the macroeconomic environment into which a policy change is injected. This could complement $\mathrm{CBO}$ 's practice of emphasizing the uncertainties associated with empirical research's inescapable imprecisions.

Third, the estimates are internally valid to minimum wage increases that were binding in a particular set of states. As emphasized by Clemens and Wither (2014), significant uncertainties come with efforts to extrapolate these estimates to minimum wage changes that may, on the surface, appear to be only marginally out of sample. At least two factors, for example, may complicate efforts to infer the effects of the full set of minimum 
wage increases implemented between 2006 and 2009. First, the minimum wage increases used for estimation involved the third increment of a three phase, $4^{0}$ percent increase in the federal minimum wage. It seems likely that the third phase would have been more substantially binding than phases one and two. Second, the increase in the federal minimum wage was only binding in states that had not voluntarily enacted higher minimum wage rates. This may well be in part because these states anticipated relatively severe disemployment effects as a result of such a change. Indeed, both income and housing price data reveal bound states to be states with lower costs of living than unbound states.

These considerations highlight the difficulty of $\mathrm{CBO}$ and JCT's tasks of projecting policy changes' impacts. Projecting aggregate budgetary impacts requires overcoming several hurdles. First, as emphasized throughout this paper, budgetary projections require a comprehensive understanding of the channels through which a given policy change can impact either revenue or expenditure. Second, such analysis requires estimates, drawing on historical experience, of similar policy changes' causal effects on the relevant behavioral and budgetary margins. Third, it requires overcoming the hurdle of external validity by assessing historical experience's relevance to the current economic and policy making environment.

\section{Conclusion}

This paper presents an analysis of the budgetary spillovers associated with the July 2009 increase in the federal minimum wage. I find that binding minimum wage increases resulted in reductions in tax collections and relatively modest changes in spending through tax-financed social insurance programs. The estimated effects on tax collections reflect the fact that, as analyzed by Clemens and Wither (2014), this set of minimum wage increases significantly decreased targeted workers' employment. Minimum wage 
changes implemented in different macroeconomic environments may, of course, result in quite different outcomes.

Illustrating the difficulty of projecting such effects is this paper's primary objective. In addition to depending on the macroeconomic conditions in which a policy is implemented, a policy change's budgetary effects depend on its interactions with other government programs. These program interactions can, in turn, be crucial for understanding a policy change's welfare implications. In this paper's application, unemployment insurance, food stamp benefits, and cash welfare turned out not to significantly cushion the income losses realized by those losing their jobs following minimum wage increases. More generally, program interactions may augment or mitigate either the intended or unintended consequences of a given policy change. Awareness of the potential for such interactions to shape a policy change's effects is essential for the execution of comprehensive cost-benefit analyses. 


\section{References}

Aizer, A. (2007): "Public health insurance, program take-up, and child health," The Review of Economics and Statistics, 89(3), 400-415.

Baicker, K., J. Clemens, and M. Singhal (2012): “The rise of the states: US fiscal decentralization in the postwar period," Journal of Public Economics, 96(11), 1079-1091.

BAICKER, K., AND N. GoRdon (2006): "The effect of state education finance reform on total local resources," Journal of Public Economics, 90(8), 1519-1535.

Baicker, K., and D. Staiger (2005): “Fiscal Shenanigans, Targeted Federal Health Care Funds, and Patient Mortality.," Quarterly Journal of Economics, 120(1), 345-386.

Bhargava, S., and D. Manoli (Forthcoming): "Psychological frictions and incomplete take-up of social benefits: Evidence from an IRS field experiment," American Economic Review.

Blank, R., and D. CARD (1991): “Recent Trends in Insured and Uninsured Unemployment: Is There An Explanation?," Quarterly Journal of Economics, 106(4), 1157-1190.

Brown, D. W., A. E. Kowalski, and I. Z. Lurie (2015): “Medicaid as an Investment in Children: What is the Long-Term Impact on Tax Receipts?," NBER Working Paper 20835 .

Burkhauser, R. V., and J. J. SAbia (2007): “The Effectiveness of Minimum Wage Increases in Reducing Poverty: Past, Present, and Future," Contemporary Economic Policy, 25(2), 262-281.

Chandra, A., J. Gruber, and R. McKnight (2010): “Patient cost-sharing and hospitalization offsets in the elderly," American Economic Review, 100(1), 193. 
Chetty, R., J. N. Friedman, and J. E. Rockoff (2013): “Measuring the impacts of teachers II: Teacher value-added and student outcomes in adulthood," NBER Working Paper 19424.

Clemens, J. (2015): "Regulatory Redistribution in the Market for Health Insurance," American Economic Journal: Applied Economics, 7(2), 109-34.

Clemens, J., and S. Miran (2012): “Fiscal policy multipliers on subnational government spending," American Economic Journal: Economic Policy, pp. 46-68.

Clemens, J., And M. Wither (2014): “The Minimum Wage and the Great Recession: Evidence of Effects on the Employment and Income Trajectories of Low-Skilled Workers," NBER Working Paper 20724.

Gordon, N. (2004): “Do federal grants boost school spending? Evidence from Title I," Journal of Public Economics, 88(9), 1771-1792.

Gruber, J. (1997): “The Consumption Smoothing Benefits of Unemployment Insurance," American Economic Review, 87(1), 192-205.

(2011): “The Impacts of the Affordable Care Act: How Reasonable Are the Projections?," NBER Working Paper 17168.

Hendren, N. (2013): “The Policy Elasticity,” NBER Working Paper 19177.

Hines, J. R., and R. H. Thaler (1995): “Anomalies: The flypaper effect,” The Journal of Economic Perspectives, pp. 217-226.

InMAN, R. P. (2008): “The flypaper effect," NBER Working Paper 14579.

Isen, A., M. Rossin-Slater, and W. R. Walker (2014): “Every Breath You Take-Every Dollar You'll Make: The Long-Term Consequences of the Clean Air Act of 1970," NBER Working Paper 19858. 
KLINE, P., ANd C. Walters (2014): “Evaluating public programs with close substitutes: The case of Head start," Discussion paper.

KNIGHT, B. (2002): "Endogenous federal grants and crowd-out of state government spending: Theory and evidence from the federal highway aid program," American Economic Review, pp. 71-92.

LeE, D., ANd E. SAEZ (2012): “Optimal minimum wage policy in competitive labor markets," Journal of Public Economics, 96(9), 739-749.

Manoli, D. S., And N. TuRner (2014): “Nudges and Learning: Evidence from Informational Interventions for Low-Income Taxpayers," NBER Working Paper 20718.

MeER, J., ANd J. West (2013): “Effects of the Minimum Wage on Employment Dynamics," NBER Working Paper 19262.

Meyer, B. D., W. K. Mok, and J. X. Sullivan (2015): "Household Surveys in Crisis," NBER Working Paper 21399.

Moffitt, R. (1983): “An Economic Model of Welfare Stigma," American Economic Review, 73(5), 1023-1035.

Murphy, K. M., AND F. Welch (1990): “Empirical age-earnings profiles,” Journal of Labor economics, pp. 202-229.

Poterba, J. (1994): "State responses to fiscal crises: Natural experiments for studying the effects of budgetary institutions," Journal of Political Economy, 102(4), 799-821.

Rothstein, J., and R. G. VAlletta (2014): “Scraping by: Income and program participation after the loss of extended unemployment benefits," Discussion paper. 
Sabia, J. J., ANd R. V. Burkhauser (2010): “Minimum wages and poverty: will a $\$ 9.50$ Federal minimum wage really help the working poor?," Southern Economic Journal, $76(3), 592-623$.

SMith, R. E., AND B. VAVRIChEK (1992): “The wage mobility of minimum wage workers," Industrial and Labor Relations Review, pp. 82-88. 


\section{Tables and Figures}
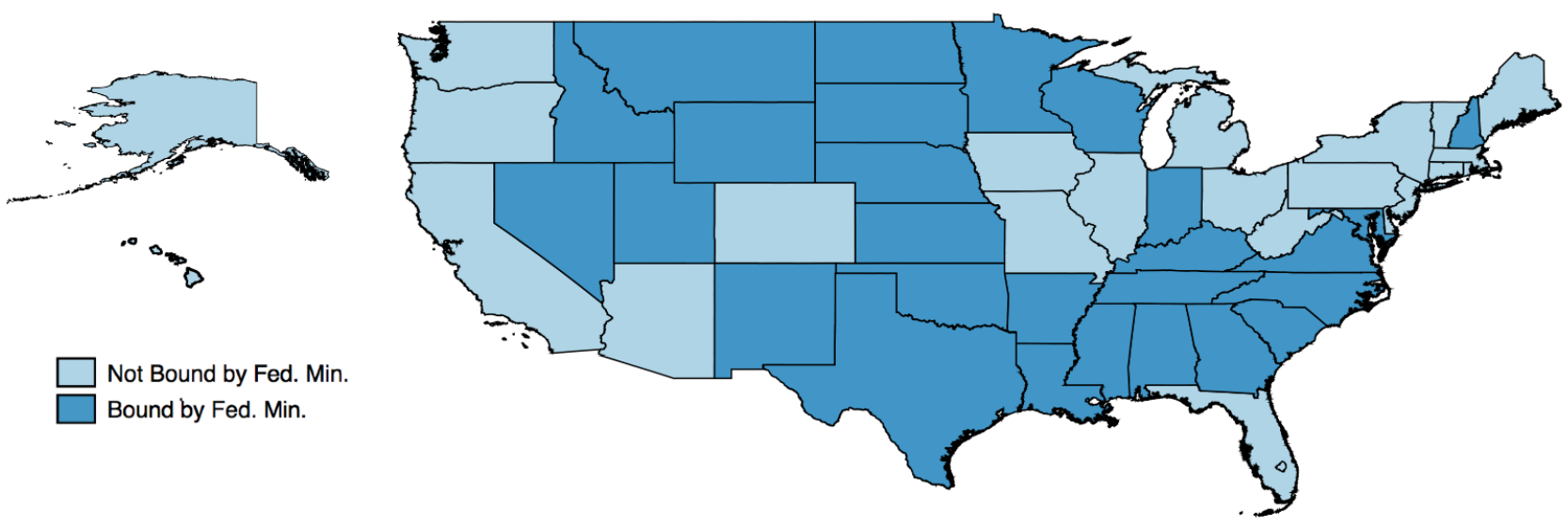

Figure 1: States Bound by the 2008 and 2009 Federal Minimum Wage Increase:

The map labels states on the basis of whether we characterize them as bound by the July 2008 and July 2009 increases in the federal minimum wage. We define bound states as states reported by the Bureau of Labor Statistics (BLS) to have had a minimum wage less than $\$ 6.55$ in January 2008. Such states were at least partially bound by the July 2008 increase in the federal minimum and fully bound by the July 2009 increase from $\$ 6.55$ to $\$ 7.25$. 


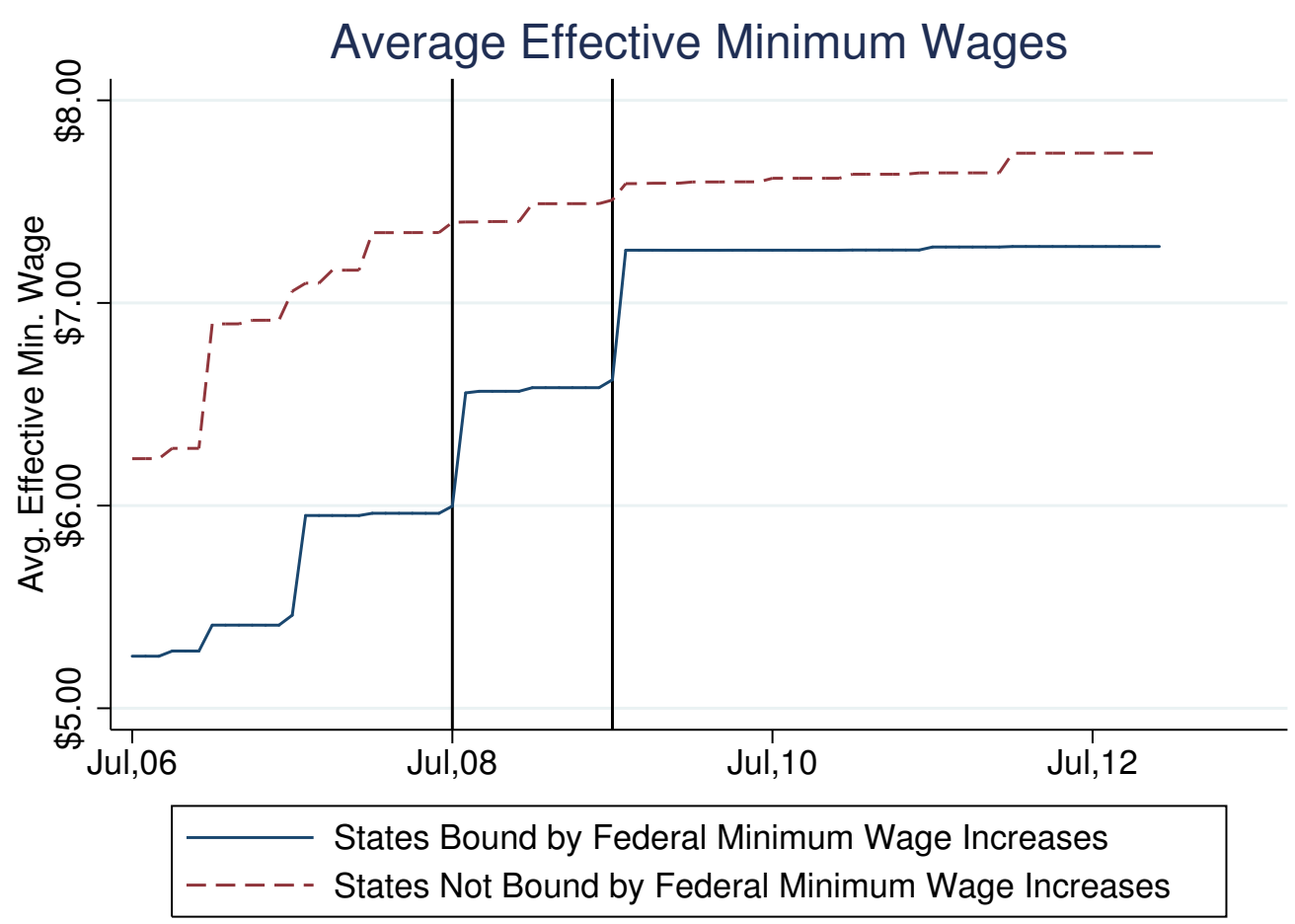

Figure 2: Evolution of the Average Minimum Wage in Bound and Unbound States:

As in the previous figure, we define bound states as states reported by the Bureau of Labor Statistics (BLS) to have had a minimum wage less than $\$ 6.55$ in January 2008. Such states were at least partially bound by the July 2008 increase in the federal minimum and fully bound by the July 2009 increase from $\$ 6.55$ to \$7.25. Effective monthly minimum wage data were taken from the detailed replication materials associated with Meer and West (2014). Within each group, the average effective minimum wage is weighted by state population. The first solid vertical line indicates the timing of the July 2008 increase in the federal minimum wage as well as the first month of data available in our samples from the 2008 panel of the Survey of Income and Program Participation. The second solid vertical line indicates the timing of the July 2009 increase in the federal minimum wage. 


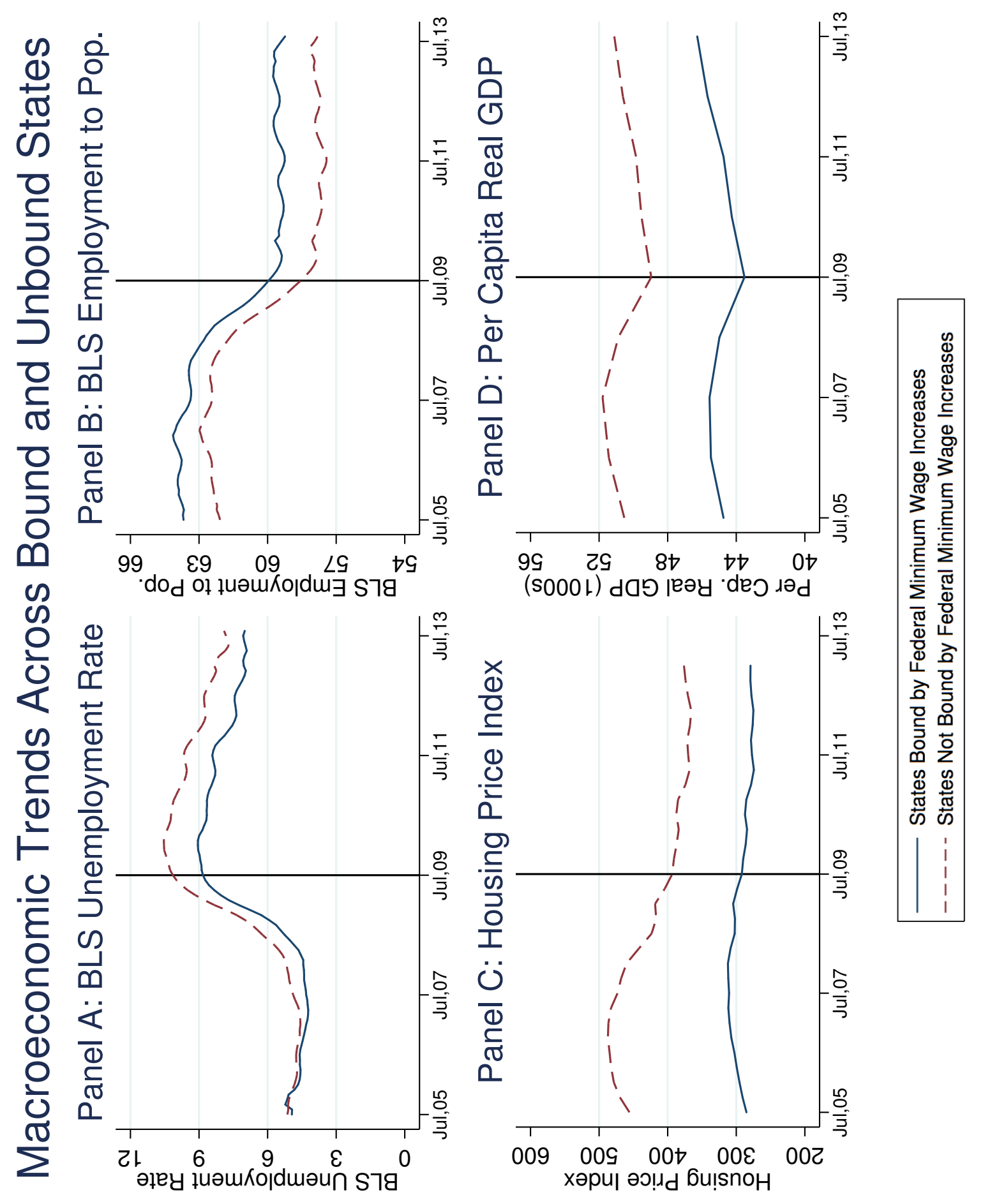

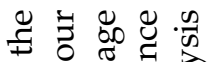

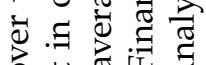

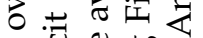

幽艺

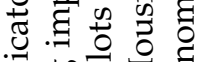

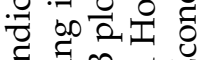

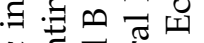

.

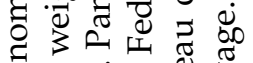

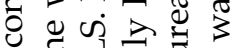

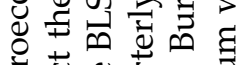

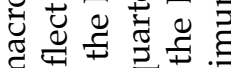

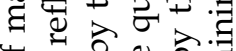

둥 응 을.

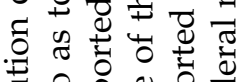

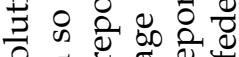

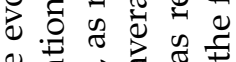

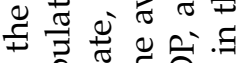

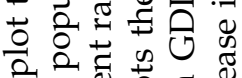

क ष

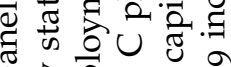

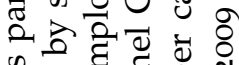

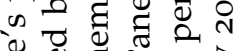

i் क.

の.

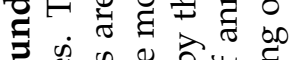

จे थ \&

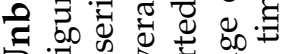

Ð

ฮั

ฮี

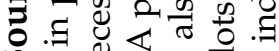

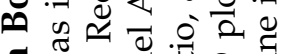

.

ஏ

ญ

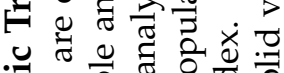

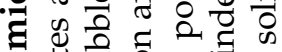

월

ชัฮ

은 Оె

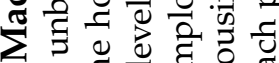

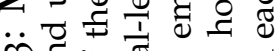
$m$ 뜌

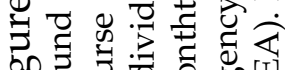
江 


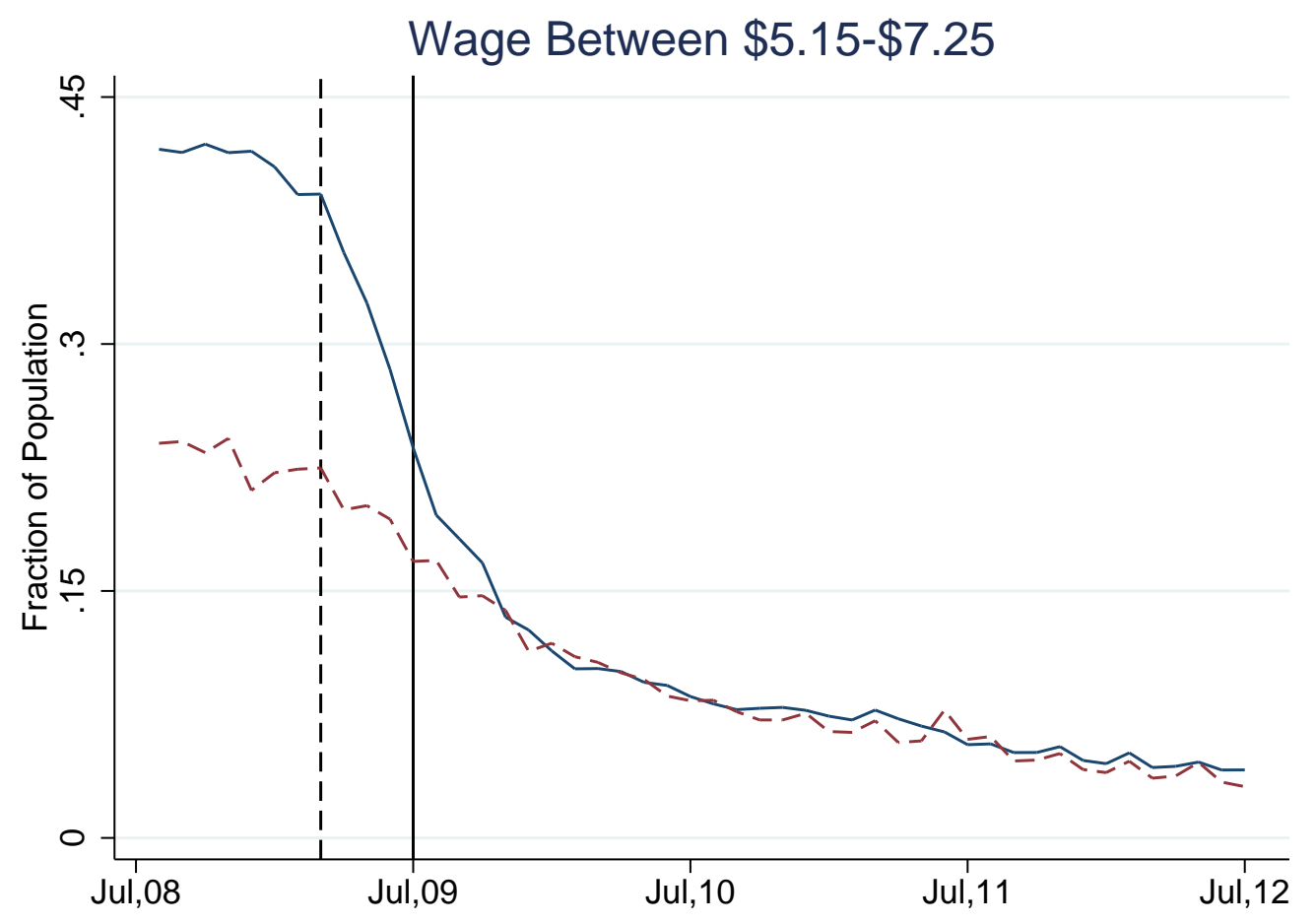

Figure 4: Evolution of the Probability of Making a Wage between \$5.15 and \$7.25:

The figure reports the fraction of individuals in the analysis sample earning a wage between $\$ 5.15$ and $\$ 7.25$. THe sample consists of the individuals whose baseline summary statistics are described in Table 1. 


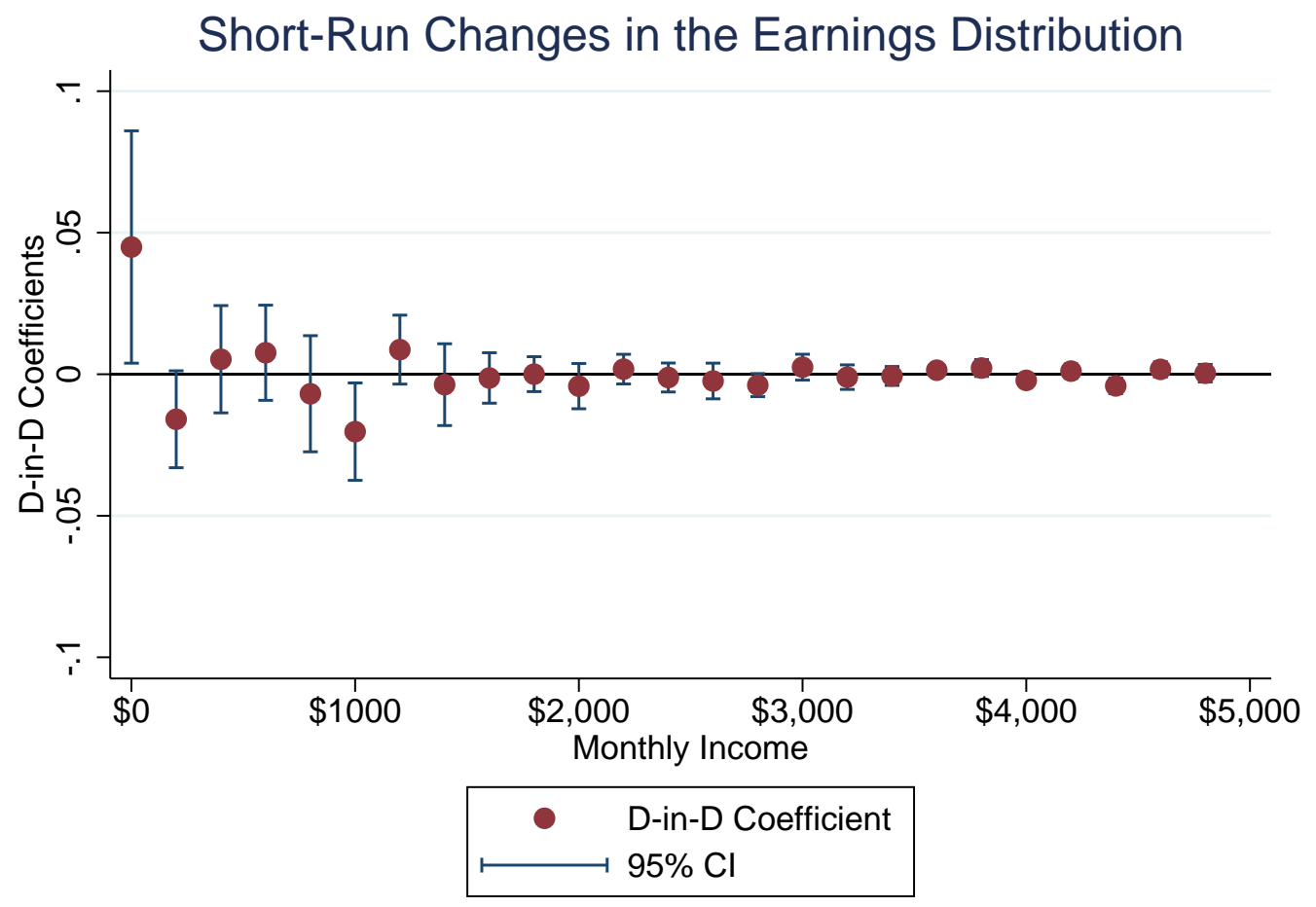

Figure 5: Short-Run Changes in the Earnings Distribution:

The figure reports estimates of binding minimum wage increase's medium run effects on the earnings distribution of low-skilled workers. Each dot is an estimate of the coefficient $\beta_{p(t)}$ from equation (1), where the relevant $p(t)$ corresponds with the period beginning in August 2009 and ending in July 2010. The dependent variables in each specification take the form $Y_{i, s, t}^{j}=1\left\{E^{j-1}<\right.$ Earnings $\left._{i, s, t}<E^{j}\right\}$. These $Y_{i, s, t}$ are indicators equal to $I$ if an individual's earnings are in the band between $E^{j-1}$ and $E^{j}$, where each band is a 200 dollar interval. The results can thus be described as estimates of the minimum wage's short-run effect on the earnings distribution's probability mass function. 


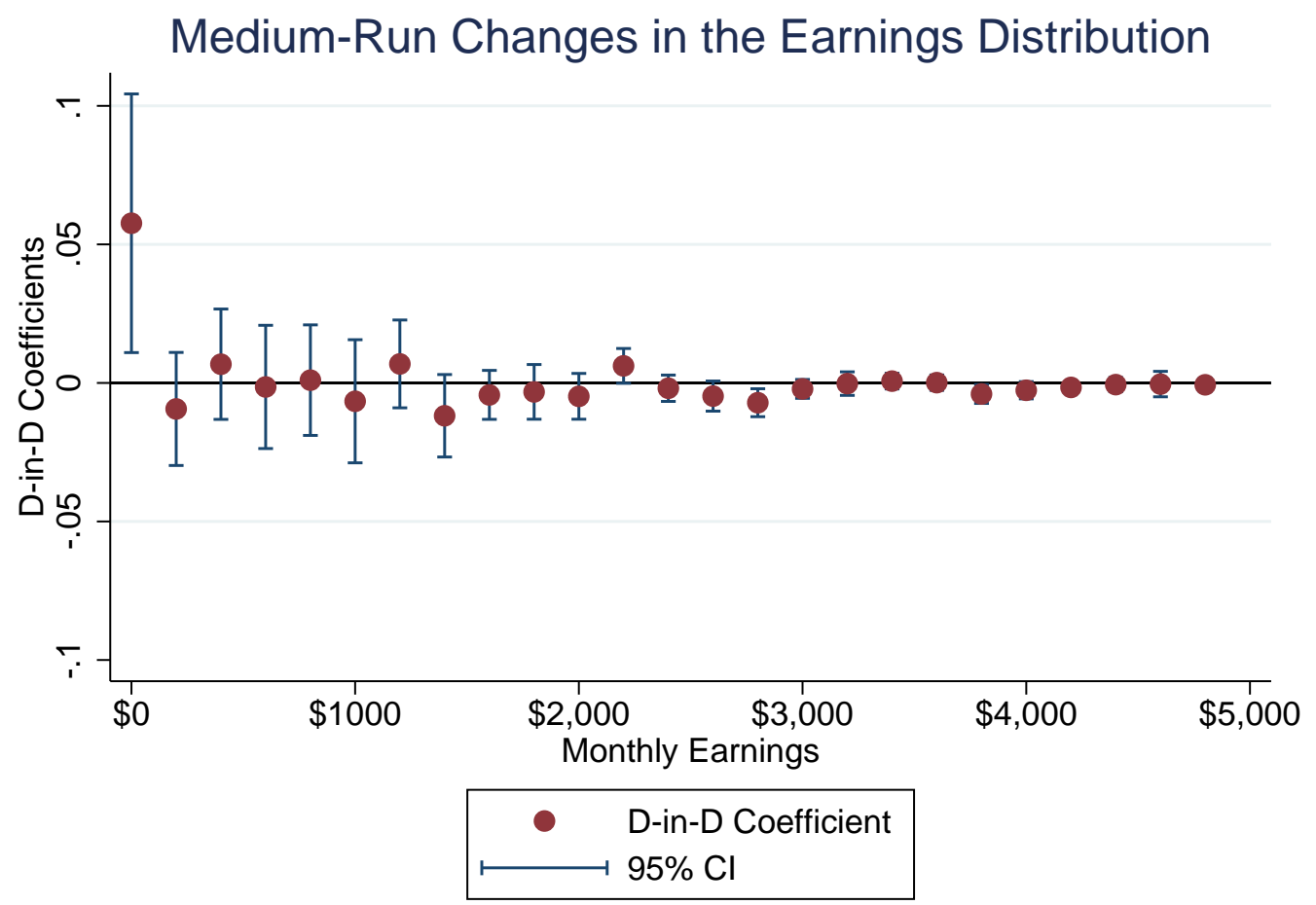

Figure 6: Medium-Run Changes in the Earnings Distribution:

The figure reports estimates of binding minimum wage increase's medium run effects on the earnings distribution of low-skilled workers. Each dot is an estimate of the coefficient $\beta_{p(t)}$ from equation (I), where the relevant $p(t)$ corresponds with the period beginning one year after the July 2009 increase in the federal minimum wage. The dependent variables in each specification take the form $Y_{i, s, t}^{j}=1\left\{E^{j-1}<\right.$ Earnings $\left.s_{i, s, t}<E^{j}\right\}$. These $Y_{i, s, t}$ are indicators equal to 1 if an individual's earnings are in the band between $E^{j-1}$ and $E^{j}$, where each band is a 200 dollar interval. The results can thus be described as estimates of the minimum wage's medium-run effect on the earnings distribution's probability mass function. 


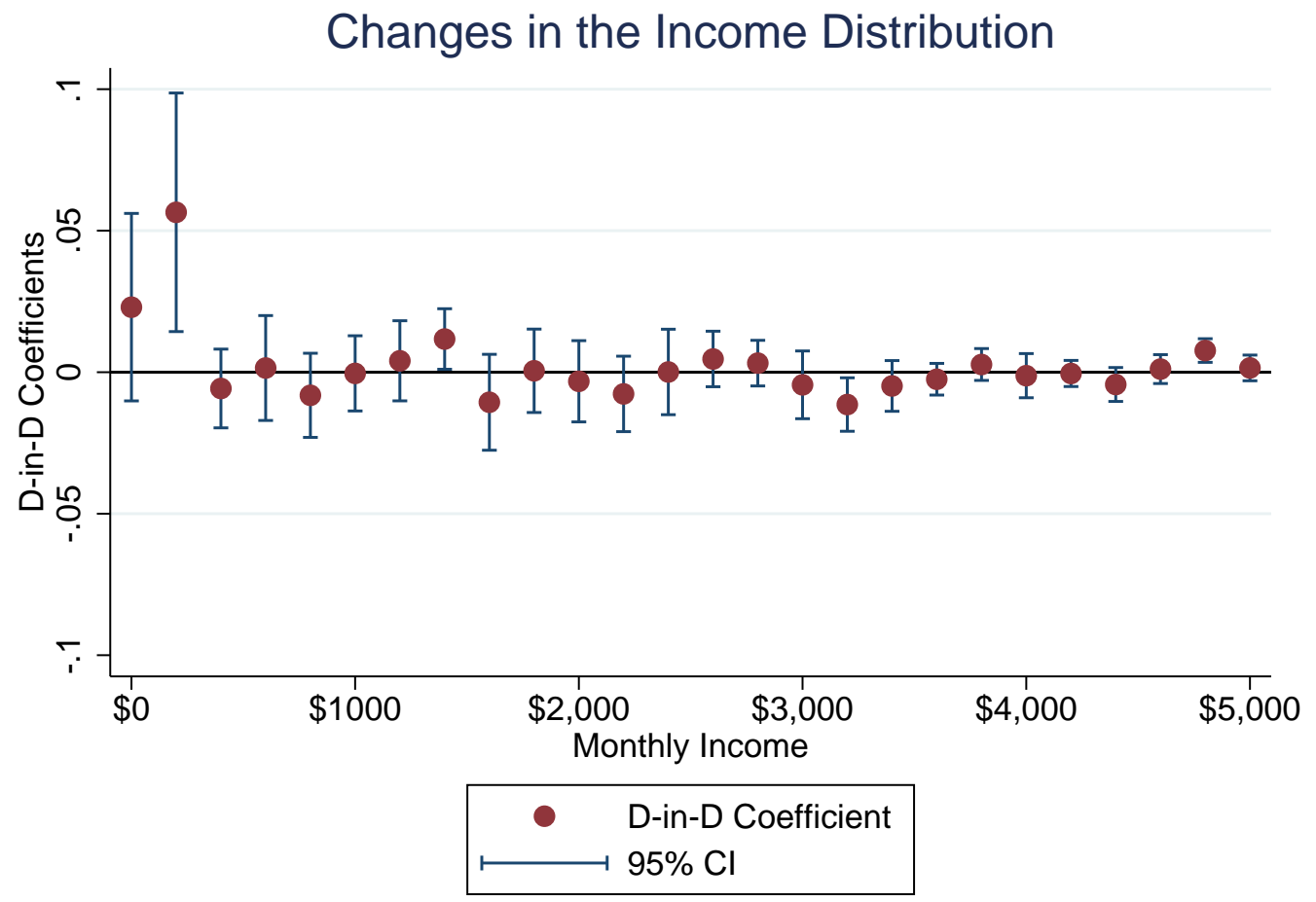

Figure 7: Medium-Run Changes in the Income Distribution:

The figure reports estimates of binding minimum wage increase's medium run effects on the earnings distribution of low-skilled workers. Each dot is an estimate of the coefficient $\beta_{p(t)}$ from equation (1), where the relevant $p(t)$ corresponds with the period beginning one year after the July 2009 increase in the federal minimum wage. The dependent variables in each specification take the form $Y_{i, s, t}^{j}=1\left\{I^{j-1}<\right.$ Income $\left._{i, s, t}<I^{j}\right\}$. These $Y_{i, s, t}$ are indicators equal to $I$ if an individual's income is in the band between $I^{j-1}$ and $I^{j}$, where each band is a 200 dollar interval. The results can thus be described as estimates of the minimum wage's medium-run effect on the income distribution's probability mass function. 


\section{Table 1: Baseline Summary Statistics by Treatment Status}

\begin{tabular}{lcc}
\hline \hline & $(1)$ & $(2)$ \\
\hline Earn \$5.15-\$7.25 & 0.373 & 0.217 \\
& $(0.484)$ & $(0.412)$ \\
Total Income & 743.7 & 754.2 \\
& $(962.0)$ & $(1008.1)$ \\
Earnings & 592.0 & 538.7 \\
& $(844.9)$ & $(823.9)$ \\
Asset Income & 23.24 & 33.79 \\
& $(242.5)$ & $(286.6)$ \\
All Other Income & 128.4 & 181.7 \\
& $(477.6)$ & $(594.1)$ \\
Means Tested Cash Transfers & 16.42 & 24.34 \\
& $(104.5)$ & $(131.0)$ \\
Food Aid & & \\
& 41.68 & 32.26 \\
Unemployment Insurance Receipts & 10.11 & 27.31 \\
& $(94.56)$ & $(215.6)$ \\
Social Security Receipts & & \\
Medicare Receipts & 38.89 & 29.11 \\
& $(205.5)$ & $(169.5)$ \\
\hline \hline & 17.17 & 15.62 \\
& $(24.50)$ & $(23.89)$ \\
\hline
\end{tabular}

Sources: Baseline summary statistics were calculated by the authors using data from the 2008 panel of the Survey of Income and Program Participation. The baseline corresponds with the period extending from August 2008 through July 2009. Columns 1, 3, and 5 report summary statistics for individuals in states we designate as bound by increases in the federal minimum, as described in the note to Figure 1. Column 2, 4, and 6 report summary statistics for individuals in the remaining states, which we designate as unbound. In Columns 1 and 2, the sample consists of individuals whose average baseline wages (meaning wages when employed between August 2008 and July 2009) are less than \$7.50. In Columns 3 and 4, the sample consists of individuals whose average baseline wages are between $\$ 7.50$ and $\$ 8.50$. In Columns 5 and 6, the sample consists of individuals whose average baseline wages are between $\$ 8.50$ and $\$ 10.00$. 


\section{Table 2: Effects on Earnings and Other Income Sources}

\begin{tabular}{lcccc}
\hline & $\begin{array}{c}\text { Total Income } \\
\text { Coeff./SE }\end{array}$ & $\begin{array}{c}\text { Earnings } \\
\text { Coeff./SE }\end{array}$ & $\begin{array}{c}\text { Property Income } \\
\text { Coeff./SE }\end{array}$ & $\begin{array}{c}\text { All Other Income } \\
\text { Coeff./SE }\end{array}$ \\
Bound x Post 1 & $-92.087^{*}$ & $-87.026^{*}$ & -12.112 & 7.051 \\
& $(36.474)$ & $(38.035)$ & $(7.446)$ & $(13.330)$ \\
Bound x Post 2 & $-144.042^{* *}$ & $-165.342^{* *}$ & -9.916 & $31.215^{+}$ \\
& $(44.748)$ & $(49.490)$ & $(8.174)$ & $(16.302)$ \\
$N$ & 147,459 & 147,459 & 147,459 & 147,459 \\
Mean of Dep. Var. & 748.459 & 567.782 & 28.034 & 152.643 \\
\hline
\end{tabular}

Note:,$+ * * *$, and ${ }^{* * *}$ indicate statistical significance at the $0.10,0.05,0.01$, and 0.001 levels respectively. The table reports estimates of the minimum wage's short and medium run effects on the relevant dependent variables, which are named in the heading of each column. More specifically, the estimates in row 1 are of the coefficient $\beta_{p(t)}$ from equation (1), where the relevant $p(t)$ corresponds with the period beginning in August 2009 and extending through July 2010. The estimates in row 2 are of the coefficient $\beta_{p(t)}$ from equation ( 1 ), where the relevant $p(t)$ corresponds with the period beginning one year after the July 2009 increase in the federal minimum wage. 


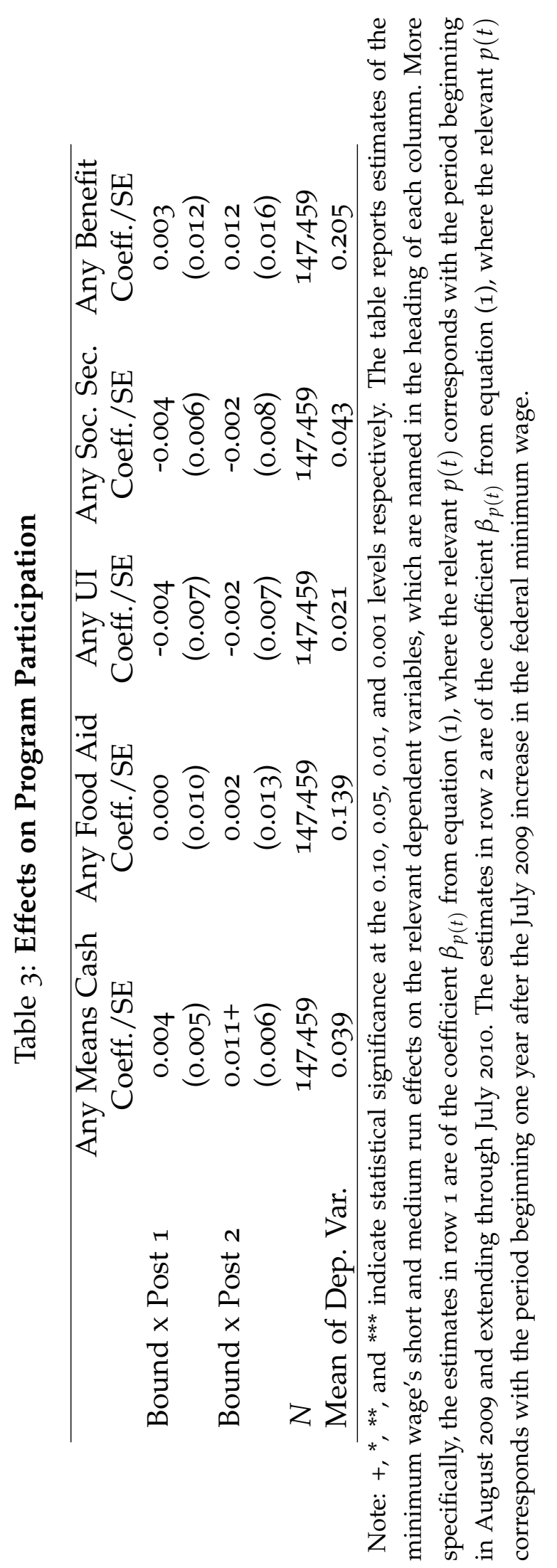




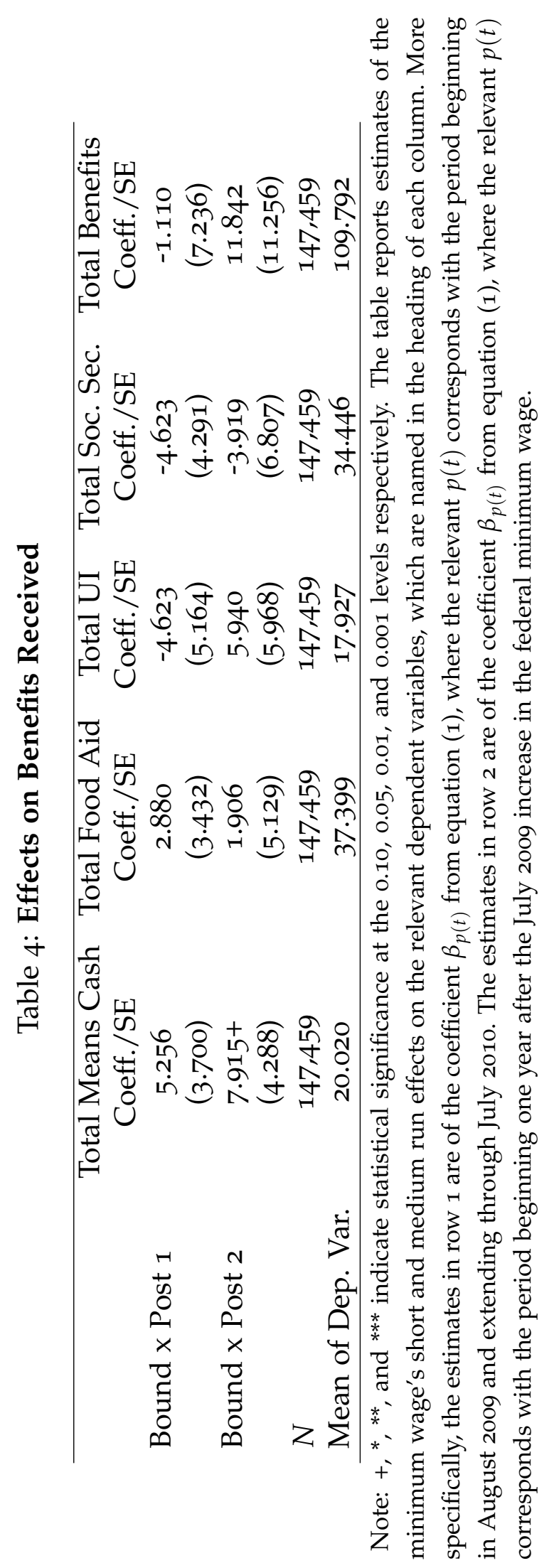




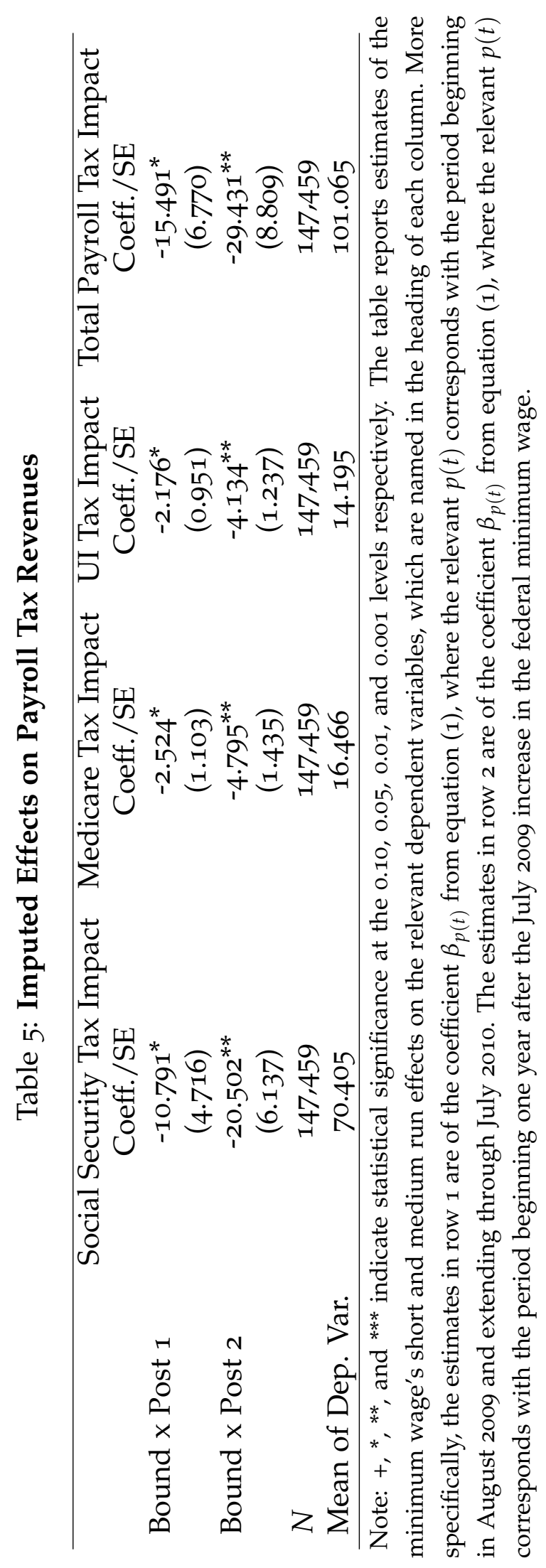

